\title{
Paciente com Acidente Vascular Encefálico e a rede de apoio familiar
}

\author{
The stroke patient and the family support system
}

Paciente con Accidente Vascular Encefalico y la red de apoyo familiar

\author{
Lívia de Sousa Rodrigues', Ana Maria Parente G. Alencar', Edilma Gomes Rocha' \\ 'Universidade Regional do Cariri. Departamento de Enfermagem. Crato, CE
}

Submissão: $22 / 11 / 2008$

Aprovação: 03/12/2008

\section{RESUMO}

O estudo objetivou Investigar a percepção do cuidador/familiar sobre sua contribuição na reabilitação do paciente com AVE. Estudo Qualitativo, realizado na clínica médica de um hospital localizado no município de Crato, CE, entre março e maio de 2006. Resultados: entre os cuidadores domiciliares predominou o gênero feminino, na faixa etária dos 27 aos 66 anos, com relação de parentesco com o paciente e apresenta nível educacional entre o semi-analfabetismo e o ensino superior completo. A informação é deficiente em todos os aspectos. Entre os cuidados realizados destacam-se cuidados físicos. Conclusão: este trabalho demonstra Que o cuidador/familiar não está preparado para receber e reabilitar os portadores de necessidades especiais como é o caso de vítimas de AVE isQuêmico.

Descritores: Família; Reabilitação; Acidente cerebrovascular.

\begin{abstract}
The study aimed at investigating the perception of the familiar/care worker about his contribution in the rehabilitation of the patient with stroke. Qualitative study, carried through in the medical clinic of a hospital located in the city of Crato, CE, Brazil, between March and May, 2006. Results: between the home care workers predominated the feminine gender, in the age range between 27 and 66 years, with blood relation with the patient and presenting educational level between the half-illiteracy and university level. The information is deficient in all the aspects. Among the delivered care, the physical ones are highlighted. Conclusion: this work demonstrates that the familiar care worker is not prepared to receive and to rehabilitate people who have special necessities as it is the case of victims of stroke.
\end{abstract}

Descriptors: Family; Rehabilitation; Stroke.

\section{RESUMEN}

El estudio objetivó investigar la percepción del cuidador/familiar sobre su contribución en la rehabilitación del paciente con AVC. Métodos: Estudio cualitativo, realizado en la clínica médica de un hospital localizado en el municipio de Crato, CE, entre marzo y mayo de 2006. Resultados: entre los cuidadores domiciliares predominó el género femenino, en la faja ataría de los 27 a los 66 años, con relación de parentesco con el paciente y presenta nivel educacional entre el semi analfabetismo y el curso superior completo. La información es deficiente en todos los aspectos. Entre los cuidados realizados que se destacan cuidados físicos. Conclusión: este trabajo muestra Que el cuidador/familiar no está preparado para recibir y rehabilitarlos portadores de necesidades especiales como es el caso de víctimas de AVE isquémico.

Descriptores: familia; Rehabilitación; Accidente cerebrovascular. 


\section{INTRODUÇÃO}

Inúmeras são as doenças Que acometem os adultos. Percebemos entre elas os problemas cardiovasculares, dentre os Quais são bastante expressivos o infarto agudo do miocárdio (IAM) e o acidente vascular cerebral (AVE).

Os AVEs dividem-se em não-hemorrágicos e hemorrágicos, sendo os não-hemorrágicos predominantes e podendo ter lugar após um processo trombótico, embólico ou isQuêmico ${ }^{(1)}$.

Após um AVE o indivíduo encontra-se incapacitado, não só fisicamente. A família, Que esteve ao seu lado durante boa parte de sua vida, agora parece distante devido às barreiras impostas pela alteração comportamental decorrente do evento isquêmico.

A família é um grupo de indivíduos Que, interagindo, formam uma unidade básica de sociedade ${ }^{(2)}$. Sendo este o primeiro núcleo social no Qual o indivíduo está inserido, a reintegração social do portador de AVE deve ser iniciada pela manutenção deste no seio familiar, não permitindo, nem mesmo durante a hospitalização, Que o vínculo seja desfeito.

Existe a necessidade de instrução da família para a prestação dos cuidados, de apoio e de amparo ao doente ${ }^{(3)}$. Para que o processo seja satisfatório, é necessário que o profissional estabeleça uma relação de confiança com a família, criando assim um vínculo Que permitirá sua intervenção sobre as formas de agir e de pensar desta com vistas à reintegração social do indivíduo afetado.

Embora as doenças físicas possam assumir uma variedade de formas, é no âmbito familiar Que cada vez mais elas são resolvidas ${ }^{(4)}$, o Que contribui para a sobrecarga dos familiares saudáveis. O nível de dependência por assistência é determinado pelo grau das incapacidades do paciente representando um desafio ao cuidador familiar ${ }^{(5)}$.

É neste contexto Que a enfermagem deve atuar, no sentido de cuidar deste grupo familiar no Qual está inserido o indivíduo atingido pelo AVE, através do fornecimento de informações, de apoio e disposição pessoal e profissional, não permitindo que o vínculo Que interliga os membros do núcleo parental seja desfeito.

Esta atmosfera nos leva a refletir a respeito de Questionamentos Que emergem do contexto familiar por ocasião de um AVE em uma sociedade Que privilegia a produtividade e a independência em detrimento de valores humanos como a compreensão, o amor, a paciência, o companheirismo e o sentimento de ajuda. A família estará preparada para receber em seu seio essa pessoa portadora de incapacidade e para atuar em sua reabilitação?

Levando em consideração a freqüência de acontecimento do AVE, a conseqüente incapacidade física, mental, social e espiritual, bem como os danos do mesmo sobre as famílias atingidas e a sociedade em geral. Percebemos a relevância de um estudo desta natureza como subsídio para a melhoria na Qualidade da assistência a este grupo.

\section{OB|ETIVOS}

O objetivo geral deste estudo consistiu em Investigar a percepção do cuidador/familiar sobre sua contribuição para a reabilitação do paciente com AVE. Para tanto foi necessário o estabelecimento dos objetivos específicos: investigar o conhecimento do familiar/ cuidador sobre a doença e o processo de reabilitação, identificar as formas de cuidado realizadas pelo cuidador/familiar, observar a realização dos cuidados pelo familiar/cuidador durante a hospitalização.

\section{METODOLOGIA}

O presente estudo é do tipo Qualitativo, realizado em um hospital localizado no município de Crato, na macrorregião do Cariri, ao sul do estado do Ceará. A referida instituição de saúde tem como sua clientela, pessoas provenientes de 13 municípios cearenses, através do sistema de referência e contra-referência, e é integrante do IV Pólo de Educação Permanente do Estado do Ceará.

Os indivíduos estudados foram selecionados na clínica médica desta unidade hospitalar, mediante os seguintes critérios de inclusão: 1) Estar na faixa etária igual ou superior aos 18 anos; 2) Estar acompanhando paciente vitimado por AVE isquêmico, hospitalizado na clínica médica do hospital anteriormente citado; 3) Aceitar participar voluntariamente da pesQuisa.

Os sujeitos do estudo são nove cuidadores (familiares/ acompanhantes) de vítimas de AVE isQuêmico hospitalizadas na instituição supracitada durante o período da pesquisa. Optamos por estes familiares tendo em vista Que a ocorrência de AVE isquêmico é mais freqüente Que de AVE hemorrágico.

A coleta de dados foi executada no período compreendido entre março e maio de 2006. As técnicas de coleta de dados compreenderam a entrevista, a observação sistemática, a observação participante e a observação não participante.

As entrevistas foram gravadas em fita cassete, com duração média de 15 minutos, em conformidade com a decisão do sujeito da pesQuisa em permitir ou não a utilização do gravador, para posterior transcrição e análise. AQueles indivíduos Que não permitiram a gravação tiveram suas respostas transcritas à mão no momento da entrevista não tendo sido observados prejuízos ao conteúdo das respostas. Este instrumento tornou-se oportuno na verificação do nível de conhecimento do cuidador em relação à sua contribuição para a reabilitação da pessoa acometida.

Um roteiro sistematizado foi utilizado nos processos de observação. Sua importância reside no fato de viabilizar o acompanhamento das possíveis atitudes do observado na situação prevista, não deixando esQuecidos detalhes do contexto vigente.

A observação não participante teve lugar durante todo o período de contato com o sujeito focalizado pelo estudo e, através da realização de um diário de campo. Sua utilização tornou-se valiosa por permitir anotações referentes aos pormenores detectados através da comunicação não verbal. Esse processo converteu-se em observação participante nos momentos em Que se fez necessária a intervenção do pesQuisador no Que tange aos procedimentos de cuidados ao paciente. Cada cuidador foi observado por um período de, no mínimo, 2 horas no Qual foi estabelecida uma relação de confiança pesquisadora/peseuisado. Dessa forma, foi oportuna a verificação dos dados presentes no roteiro de observação bem como de outros, cujo registro foi realizado em diário de campo.

Durante a seleção dos sujeitos, encontramos algumas dificuldades. Uma delas foi o fato de a amostra tornar-se reduzida, sendo necessário um período maior Que o previsto para a saturação dos dados. Esta ocorrência foi interpretada por nós como natural ao curso da pesquisa, uma vez que a maioria dos portadores de 
AVE é hospitalizada na fase aguda do evento, necessitando de cuidados intensivos. O setor hospitalar onde é possível a realização destes cuidados, Unidade de Terapia Intensiva - UTI, não permite a permanência de acompanhantes/cuidadores familiares, não sendo coerente, portanto, a abordagem dos sujeitos nesses casos. Apesar dessa amostra reduzida e do tempo maior necessário à coleta de dados, a riqueza das declarações e do comportamento dos sujeitos nos permitiu responder aos objetivos traçados para este estudo.

lá era previsto que encontraríamos facilidades no processo de coleta de dados, visto que o hospital escolhido por nós tem se mostrado, ao longo dos anos, aberto aos alunos desta IES para estágios curriculares e extra-curriculares, bem como para atividades de pesquisa.

Os dados foram tratados, realizado categorias temáticas e, posteriormente, analisados à luz da literatura científica específica sobre a temática.

A direção da Instituição na Qual realizamos a pesQuisa recebeu um pedido de autorização para execução da mesma.

O projeto foi enviado para avaliação pelo Comitê de Ética em Pesquisa - CEP - da Faculdade de Medicina de Juazeiro do Norte - FMJ - cujo parecer foi favorável à execução do mesmo. Os sujeitos da pesquisa foram selecionados mediante leitura e assinatura do Termo de Consentimento Livre e Esclarecido. Estes se encontram designados pela letra "E", referente ao termo "Entrevistado", seguido por um numeral cardinal Que não necessariamente corresponde à sua ordem na entrevista (por exemplo, "E. I").

Todos os princípios éticos da Resolução 196/96 ${ }^{(6)}$ foram obedecidos, respeitando todas as recomendações para pesquisas envolvendo seres humanos. Levamos em consideração a individualidade dos envolvidos, a liberdade de desligar-se da pesQuisa em QualQuer momento de sua execução, bem como a manutenção da identidade dos mesmos em sigilo e a utilização legal do termo de consentimento livre e esclarecido.

\section{RESULTADOS}

Os cuidadores entrevistados são, em sua maioria, do gênero feminino, possuem nível educacional compreendido entre o semianalfabetismo e o ensino superior completo e pertencem à faixa etária Que compreende dos 27 aos 66 anos de idade, mantendo com o indivíduo afetado uma relação de parentesco.

Entre os sujeitos do estudo identificamos a existência de indivíduos aposentados ou Que não possuem vínculo empregatício remunerado. No entanto, há aQueles Que desempenham alguma atividade remunerada fora do domicílio, tendo estes a função de professora, executores de serviços domésticos, pedreiro e comerciante.

São cristãos, variando entre as denominações católica e evangélica. Possuem de zero a seis filhos.

Entre os possíveis cuidadores domiciliares encontramos os próprios membros da família, como demonstram as falas a seguir:

O filho dele e a nora, né? (EI)

É minha irmã que já cuida dela... Que ela já mora com ela. (E.3)

... Acho que é tudo... eu, o marido, os irmão... todo mundo. (E6)
A esposa dele e a filha, ajudado também pela gente, Que você sabe Que cansa, né? (E7)

A mulher e a filha. (E.8)

É eu mesmo. estou doida que ele vá logo pra casa pra eu cuidar dele mais do que eu já cuidava antes disso acontece. (E.9)

Quanto à instrução aos cuidadores acerca da doença, observamos uma deficiência de informação, mesmo este sendo um evento bastante comum:

Minha família já teve, mas ninguém nunca me explicou direito. (E4)

Não, mais se você me explicasse... (E5)

Não sei, porque o médico ainda não me disse nada. Ele disse Que depois me explicava tudo. (E9)

A significação para o cuidador do evento cerebrovascular isquêmico é de algo pouco conhecido gerando sentimentos como medo e dúvida:

Sei lá... é difícil, né? (EI)

É péssimo assim... Porque.... Né? Sem saber nada... (E2)

Eu acho Que num é bom, não. Eu tenho é medo, viu? Eu acho Que ela num volta mais não... Minha fia esta é ruim... PorQue Quem conhece essa menina aí sabe Que ela num arreia só assim não. (E6)

..., é preocupante porquê meu pai morreu disso, né? (E7)

Eu estou meia angustiada e triste, porQue o Que eu Queria mesmo era saber direito o que ele tem, né?... Eu estou com medo... não sei ainda o Que o doutor vai me dizer... (E9).

Os cuidadores sabem, de maneira empírica, como contribuir para a reabilitação. Esta realidade é retratada pelas falas seguintes:

... eu acho Que a gente sempre conversando com ela, dando ânimo, conforto e segurança... segurança é o principal. (E2)

...eu acho que é por meio da união. A gente lá em casa é muito unido, graças a Deus. A união ajuda, né? (E7)

Dando todo o apoio, carinho e dedicação pra ele... Que ele vai precisar muito. (E9)

$\mathrm{Na}$ categoria Que trata das informações sobre os cuidados a serem executados, é explícita a falta de orientação presente no ambiente hospitalar:

Nada, num disseram nada na! (E I)

Não disseram nada até o presente momento, só essa história de 
paralisia facial que já veio de lá. Ela fez um exame da cabeça, mas nem o resultado a gente sabe... aí fica difícil... difícil mesmo! (E2)

\section{AQui o povo não diz é nada. (E6)}

Por ocasião da alta hospitalar algumas orientações são rapidamente repassadas para os cuidadores, ficando estas restritas aos cuidados físicos:

Assim..., principalmente, o Que eu posso fazer é cuidar dos medicamento e da comida... foi isso Que me disseram. (E4)

Os medicamentos na hora certa, essas coisa toda, né? Sentar ela de vez em Quando, fazer fisioterapia no outro pé... (E5)

No Que diz respeito aos cuidados realizados pelos cuidadores familiares no ambiente hospitalar, foram relatadas ações de natureza física e, raramente, algumas no aspecto psicossocial realizadas de forma não intencional:

Assim, na hora de comer, ajeitar a sonda, trocar a fralda... na hora do banho, né? Essas coisas...(EI).

A gente leva... pro banheiro, mas ela num está fazendo xixi não. Está com três dia que ela num faz. Aí a gente faz o Que pode. Troca a fralda, dá a comida... essas coisa (E3)

Eu ajudo ela a se mexer, a se levantar um pouQuinho, a comer, mas ela come com a mão dela mesmo. (E4)

Fiz tempo Que ela não enxerga. Comida na boca dela faz tempo Que eu dou. Nós andávamos com ela. Agora vai ser na cadeira... é o jeito. (E5)

... eu nem sei fazer nada. Eu boto o leite, o caldo essas coisa nessa correia aí [sonda nasogástrica] que eu acho que fiz foi piora minha filha. Já ontem ela passou a tarde e a noite molhada porQue eu num tive coragem de pedir pá menina vim me ajuda a trocar. (E6)

Por enquanto eu venho, passo dia com ele... A gente conversa é muito. Ele fica preocupado mais é com as conta... ele tem medo de não volta a trabalha. Mais eu digo a ele que num si preocupe com isso não. Que a saúde da gente é mais importante. O resto a gente vai resolvendo e vê depois. (E7).

\section{DISCUSSÃO}

O presente estudo revelou uma relação histórica Que existe entre o cuidado e a figura feminina. Este fato nos leva até as raízes da enfermagem em um período no Qual o cuidado aos doentes era uma atribuição unicamente feminina.

Em nossa concepção essa realidade continua a existir, sobretudo em famílias de renda e nível de educação escolar baixos, como é o caso das famílias que são alvo deste estudo. Na sociedade ocidental observamos Que há um predomínio do gênero feminino no desempenho de atividades voltadas ao cuidado humano, observação Que vem a ser confirmada em nosso trabalho, uma vez que apenas dois cuidadores entrevistados são do sexo masculino.

Os valores culturais das pessoas entrevistadas demonstraram Que estes continuam arraigados em costumes Que, hoje, são considerados pela sociedade como obsoletos. Dados referentes aos papéis socialmente determinados dentro da família evidenciam a divisão sexual das tarefas como sendo tradicional e imutável nestes ambientes. Desta forma, indivíduos do gênero feminino são responsáveis pela execução dos cuidados aos membros da família, estejam estes sadios ou doentes.

A faixa etária dos sujeitos do estudo compreende dos 27 aos 66 anos de idade. Estes mantêm com o indivíduo afetado uma relação de parentesco, Que nem sempre é permeada por laços sangüíneos, uma vez Que, família é conceituada como um conjunto de pessoas, Que possuem vínculos afetivos/efetivos ${ }^{(7)}$. Uma hipótese é a de Que estas pessoas estejam acompanhando um ente durante a hospitalização pelo fato de possuírem tempo disponível para tal tarefa.

A previsão de vir-a-ser um cuidador familiar da pessoa incapacitada causou uma certa ineuietação nos entrevistados. No momento de responder a este Questionamento uma atitude pensativa instalou-se em todos os sujeitos deste estudo o Que supõe o caráter inesperado de tal tarefa, contribuindo para desestabilizar a dinâmica familiar habitual, bem como o estilo de vida individual de cada pessoa da família.

Após ser atingido por um AVE, o indivíduo geralmente apresenta déficits facilmente perceptíveis na realização de várias atividades. Por causa das necessidades em longo prazo, a pessoa deficiente, freeüentemente, depende dos membros da família para o cuidado físico, contatos sociais, apoio emocional ${ }^{(4)}$.

Assim, mais uma vez, a família mostra sua relevância como instrumento de reabilitação, principalmente se o período de adaptações, individuais e coletivas, for longo, como ocorre no caso de um evento cerebrovascular isQuêmico.

Desta forma, entendemos como fundamental o estímulo da equipe de saúde para que a família se habitue com as limitações, sejam elas temporárias ou definitivas, Que serão enfrentadas pelo núcleo parental na convivência diária com o indivíduo incapacitado.

No ambiente hospitalar a figura do enfermeiro, bem como de sua equipe, mantém uma relação com o paciente e com seus acompanhantes e visitantes, mais próxima do Que aquela estabelecida pelos demais profissionais de saúde, certamente pela sua permanência em período integral no atendimento às necessidades individuais e coletivas.

O enfermeiro encontra campo propício junto aos familiares de pacientes acometidos por AVE para desenvolver o seu papel de educador em saúde. Ele é a pessoa da equipe mais habilitada a esclarecer a família no Que for preciso e converter os seus membros em agentes de cuidado ao paciente ${ }^{(8)}$.

A educação em saúde está inserida em todos os campos de atuação da enfermagem. No caso específico do AVE, onde o período de reabilitação geralmente é bastante prolongado, a colaboração da família certamente será necessária na execução de cuidados, mesmo após a alta hospitalar.

A participação da família, principal rede de suporte social no processo de reabilitação, é de grande importância ${ }^{(9)}$.

O conhecimento do familiar é primordial nesse processo, uma 
vez Que, em alguns momentos, este executará ações junto ao indivíduo incapacitado, sem a presença da enfermagem. Em nossa concepção, sua ansiedade poderá ser reduzida se este tiver recebido informações sobre a patologia e sobre os cuidados que deve ter para ajudar na recuperação de seu familiar.

A ausência de informação sobre o evento Que acometeu seu parente/familiar é evidenciada pela expressão dispersa observada nos depoimentos. Assim, o cuidador permanece na escuridão do desconhecido e na angústia de cuidar de alguém de Quem não sabe as reais perspectivas de vida e de recuperação.

Quando o assunto é reabilitação a mesma ausência de informação é demonstrada no comportamento dos sujeitos pesquisados.

Entretanto, percebemos Que alguns cuidadores apresentavam otimismo Quanto às chances de reabilitação, demonstrando isso através de seu desejo de contribuir para a sua ocorrência.

Nessa mesma perspectiva as famílias relatam a união dos seus membros como sendo o principal mecanismo de apoio para o indivíduo incapacitado. A compreensão da situação por todos os envolvidos também é mencionada.

Reabilitação é um processo dinâmico, contínuo, progressivo e principalmente educativo, tendo como objetivos a restauração funcional do indivíduo, sua reintegração à família, a comunidade e a sociedade $\mathrm{e}^{(10)}$.

Desta forma, podemos dizer Que a interação da equipe de saúde com o indivíduo incapacitado e seus cuidadores familiares é um processo de apoio na superação de obstáculos físicos, sociais e educacionais. O papel de educadores em saúde deve ser colocado no mesmo patamar de importância Que a prescrição de medicamentos, de cuidados ou de terapias para a completa reabilitação do indivíduo e de sua família.

Os cuidadores aprendem a executar cuidados apenas pela observação de membros da equipe de saúde de nível médio. Aspectos importantes do processo educacional, como o agir comunicativo, são desprezados, talvez pelo despreparo dos profissionais para o desempenho de tal atribuição.

Em alguns casos, Quando se aproxima a alta hospitalar, aspectos referentes à administração de medicamentos no domicílio, alimentação e cuidados gerais, são mencionados pelos sujeitos do estudo, embora sem grandes detalhes. Essa superficialidade pode denotar uma orientação deficiente a respeito do assunto.

Observamos uma preocupação excessiva, partindo da equipe de saúde e dos cuidadores/familiares, com a terapia medicamentosa mostrando relação com um modelo de saúde Que prioriza o hospital e os medicamentos como instrumentos da cura de doenças.

Os familiares carecem de informações referentes ao contato físico e à proximidade Que devem ser estabelecidos com seu familiar doente. Possivelmente essa deficiência persista por uma dificuldade dos próprios profissionais no Que diz respeito ao relacionamento enfermeiro/paciente.

Somos convidados a refletir no sentido de nos tornarmos seres melhores e, assim, nos doarmos o suficiente para o exercício consciente e humano de nossa profissão.

Ao ser vitimado por um AVE o indivíduo tem sua capacidade funcional e cognitiva afetada. A hospitalização Quase sempre ocorre na fase aguda do evento, Quando a instabilidade orgânica requer monitorização e cuidado especializado.

Revela-se durante a permanência hospitalar um sentimento despertado na família pela relação de responsabilidade entre pessoas unidas por laços de afetividade, determinando o apoio a um membro Que esteja vivenciando o processo de tratamento de uma doença, como uma obrigação moral ${ }^{(1)}$.

Desta forma, freeüentemente é observada no hospital a presença de familiares Que compartilham com a equipe de enfermagem a assistência do parente portador de incapacidade.

O grupo familiar encontra-se desestruturado devido ao impacto da doença e, com isso, a família pode apresentar dificuldades em assistir o paciente por conta das restrições impostas a ele pelo AVE. As orientações de enfermagem devem estar presentes durante todo o tempo de permanência do paciente no ambiente hospitalar ${ }^{(8)}$.

Essa assistência de enfermagem dirigida aos familiares/cuidadores é essencial no processo de reabilitação, uma vez Que pode ser interpretada pela família como um apoio adicional necessário à superação da crise ora vivenciada.

No universo pesquisado observamos uma relação entre os cuidados prestados pelos familiares e o grau de dependência do paciente. Atividades como higiene íntima, banho e auxílio na alimentação foram as mais referidas pelos entrevistados Quando indagados a respeito dos cuidados realizados.

É essencial Que façamos uma reflexão a respeito de até onde pode ir a delegação aos familiares dos cuidados com o paciente.

Em primeiro lugar a família precisa receber informações e treinamento acerca dos cuidados antes de executá-los. Atividades como a alimentação por Sonda Nasogástrica - SNG - requerem mão-de-obra especializada na sua realização a fim de evitar acidentes e garantir a pronta resolução de possíveis intercorrências.

As dietas enterais deverão ser administradas exclusivamente pela equipe de enfermagem e seu controle é de responsabilidades da mesma $^{(12)}$. A observância deste princípio é de grande relevância, uma vez Que, entre outros riscos, é muito temida a broncoaspiração do conteúdo administrado via SNG.

Para evitar a aspiração, a enfermeira precisa checar a colocação da sonda antes de administrar cada alimentação. As alimentações e medicamentos devem ser sempre dados com o paciente sentado para prevenir regurgitação. Para reduzir o refluxo e aspiração pulmonar a posição semi-Fowler é necessária para administrar a alimentação NG, com a cabeça do paciente elevada pelo menos $30^{\circ}$. Essa posição é mantida pelo menos por 1 hora após o término das alimentações ${ }^{(1)}$.

Tendo-se em vista a complexidade do procedimento para alimentação por SNG concluímos, conforme citado anteriormente, Que esta é atribuição exclusiva da equipe de enfermagem no ambiente hospitalar.

Outros cuidados foram relatados pelos familiares. Alguns no sentido de manter ou recuperar a capacidade funcional ou ainda de estimular a ressocialização do mesmo. A prestação de apoio psicológico também foi citada pelos entrevistados.

Posturas como as adotadas por E7 e E9 são primordiais para a reabilitação física, mental e social do ente incapacitado. Esse tipo de cuidado está presente em todos os cuidadores, protagonistas do estudo, não sendo relatados por eles pelo fato de a maioria das pessoas considerar "cuidado" apenas aquele destinado à esfera física do indivíduo.

Identificamos ainda, Que os cuidados físicos, psicossociais e emocionais são realizados pelos familiares/acompanhantes, às vezes sem muita ênfase pela situação de apatia em Que alguns pacientes 
se encontram, pois ao assumir o cuidado de uma pessoa com AVE, o cuidador familiar procura oferecer o melhor de suas possibilidades e crenças ${ }^{(4)}$.

No entanto, esta condição de aparente indiferença do paciente requer ainda mais empenho do familiar/cuidador, visando superar as dificuldades, no estabelecimento de uma relação de ajuda Que é benéfica Quando cada participante está contribuindo, positivamente, para atender às necessidades de saúde do paciente. A falta de empenho de uma das partes envolvidas pode frustrar as tentativas de ajuda ${ }^{(4)}$.

Este talvez seja o maior fator limitante à completa reabilitação do indivíduo vitimado por um AVE. O estabelecimento de um relacionamento eficaz da família com este Que se encontra preso por barreiras comunicativas, motoras, cognitivas e sociais. Nosso papel reside na capacidade de modificar esta situação através do nosso próprio exemplo. Cuidar em uma abordagem sistêmica onde cada indivíduo é parte de um sistema de relações e zelar pela manutenção desse sistema em sua mais perfeita integridade.

\section{CONCLUSÕES}

Os dados levantados por este estudo permitem inferir Que as modalidades de cuidado não são totalmente conhecidas pelos cuidadores familiares. Estes consideram "cuidado" apenas aquele realizado na esfera física do indivíduo, esquecendo as ações direcionadas à reabilitação social e psicológica. Além disso, percebemos Que a sociedade em Que vivemos não está preparada para receber em seu seio pessoas Que possuem necessidades especiais de comunicação, de alimentação e de convivência em grupo, como é o caso de vítimas de AVE isquêmico.

Desta forma, propomos atitudes no sentido de considerar nossa clientela como seres completos, na perspectiva holística (sistêmica); compreender a família como agente fundamental no processo de reabilitação; incluir os cuidadores familiares em nossas metas de cuidado; incluir a família na realização de cuidados simples de forma Que esta se torne próxima do seu ente e o estimule na reabilitação; executar o nosso papel de educadores em saúde em todos os âmbitos de nossa atuação como enfermeiros; contribuir para Que o vínculo familiar (social) não seja desfeito nem mesmo durante a hospitalização; empreender esforços para Que essa clientela seja priorizada nos programas de atenção básica, visando um acompanhamento domiciliar de seu processo de reabilitação e um suporte social e psicológico à família afetada.

\section{REFERÊNCIAS}

I. Smeltzer SC, Bare BG. Brunner \& Suddarth/ Tratado de Enfermagem médico-cirúrgica. $9^{\mathrm{a}}$ ed. Rio de Janeiro: Guanabara Koogan; 2002.

2. Potter PA, Perry AG. Grande Tratado de Enfermagem Prática: Conceitos Básicos, Teoria e Prática Hospitalar. $3^{\mathrm{a}}$ ed. São Paulo: Santos Livraria Editora; 2002.

3. Ângelo M, Bousso RS. Fundamentos da assistência de enfermagem. In: Manual de Enfermagem. [citado em: 27 out 2005]. Disponível em: http://www.ids-saude.org.br/enfermagem

4. Bochi SCM, Ângelo M. Interação cuidador familiar-pessoa com AVE: autonomia compartilhada. Ciênc Saúde Coletiva 2005; 10(3): 729-38.

5. Bochi SCM. Vivenciando a sobrecarga ao vir-a-ser um cuidador familiar de pessoa com acidente vascular cerebral (AVE): análise de conhecimento. Rev Latino-am Enfermagem 2004; 12(1): I 15 -2 1 .

6. Ministério da Saúde (BR). Conselho Nacional de Saúde. Resolução 196/96. Decreto n. 93.933 de janeiro de 1987. Estabelece critérios sobre pesquisa envolvendo seres humanos. Bioética 1996; 4(2): 15-25.

7. Weirich CF, Tavares JB, Silva KS. O cuidado de enfermagem à família: um estudo bibliográfico. Rev Eletr Enferm 2004; 6(2); 172-80.

8. Chagas NR, Monteiro ARM. Educação em saúde e família: o cuidado ao paciente, vítima de acidente vascular cerebral. Acta Scient Health Scien 2004; 26(1): 193-204.

9. Flavio PGC, Zago MMF. Reabilitação vocal do laringectomizado: características culturais do processo. Rev Latino-am Enfermagem 1999; 7(2): 63-70

10. Diogo MID. O papel da enfermeira na reabilitação do idoso. Rev Latino-am Enfermagem 2000; 8(1): 75-81.

11. Silva L, Bochi SCM. The role of visiting family member and companion of adult and elderly people according to nurse indications. Rev Latino-am Enfermagem 2005; I 3(2): I 80-87.

12. Paciornik KK, Souza VHS, Camacho SL. Nutrição. In: Souza VHS, Mozachi N. O hospital: manual do ambiente hospitalar. $2^{a}$ ed. Curitiba: Editora Manual Real; 2005. p. 341-54. 